\title{
Tolerância de Híbridos de Milho ao Herbicida Nicosulfuron ${ }^{1}$
}

\author{
Tolerance of Corn Hybrids to Nicosulfuron
}

\begin{abstract}
PEREIRA FILHO, I.A. ${ }^{2}$, OLIVEIRA, M.F. ${ }^{3}$ e PIRES, N.M. ${ }^{4}$
RESUMO - Com o objetivo de avaliar a tolerância dos híbridos de milho BRS 3060, 3101, 2114 e 2110 a doses crescentes do herbicida nicosulfuron, foi instalado um ensaio de campo na área experimental do Centro de Pesquisa da Embrapa Milho e Sorgo, município de Sete LagoasMG, durante o ano agrícola 1998/1999. A densidade de plantio foi de 50.000 plantas por hectare, e as doses do nicosulfuron foram de 50, 60 e $70 \mathrm{~g}$ i.a. ha ${ }^{-1}$, mais um tratamento testemunha que não recebeu aplicação do produto, mas que permaneceu limpo durante todo o ciclo da cultura. O delineamento experimental adotado foi em blocos ao acaso com três repetições, em esquema fatorial $4 \times 4$. A aplicação do produto foi realizada quando as plantas de milho se encontravam no estádio de quatro a seis folhas, ou seja, 20 dias após emergência das plantas. As avaliações de fitotoxicidade foram feitas aos 7, 14 e 21 dias após aplicação dos tratamentos herbicida. Somente o BRS 3060 permaneceu com efeito fitotóxico muito leve nas avaliações realizadas aos 14 e 21 dias após aplicação, sem comprometer o rendimento de grãos. Os resultados indicam que o herbicida nicosulfuron pode ser aplicado para o controle de plantas daninhas em híbridos de milho BRS 3060, 3101, 2114 e 2110 nas doses de 50 a 70 g i.a. ha ${ }^{-1}$, sem causar danos significativos ao desenvolvimento e à produção da cultura.
\end{abstract}

Palavras-chave: seletividade, rendimento de grãos, planta daninha.

\begin{abstract}
This experiment was carried out at Embrapa Milho e Sorgo Experimental Station, Sete Lagoas-MG, Brazil, to evaluate the tolerance of corn hybrids BRS 3060, 3101, 2114 and 2110 to different rates of nicosulfuron, during the growing season of 1998/1999. Corn plant density was 50,000 plants per hectare and nicosulfuron rates were 50, 60 and $70 \mathrm{~g}$ a.i. ha $\mathrm{plus}^{-1}$ one control treatment, without herbicide. However, this treatment was kept weed free. The experiment design was a randomized block with 3 replications in $4 \times 4$ factorial design. Nicosulfuron was sprayed at the stage of 4 to 6 leaves, or 20 days after crop emergence. Phytotoxicity evaluation was at 7, 14 and 21 days after nicosulfuron application. Only BRS 3060 presented very low tolerance to nicosulfuron in the period of 14 and 21 days after herbicide application but grain yield was not affected. The results showed that nicosulfuron can be sprayed to control weeds in corn hybrids BRS 3060, 3101, 2114 and 2110, at the rates of 50 and $70 \mathrm{~g}$ i.a. ha $\mathrm{h}^{-1}$ of nicosulfuron without causing significant injury to the crop and affecting crop yield.
\end{abstract}

Key words: selectivity, grain yield, weed.

\section{INTRODUÇÃO}

A tolerância diferencial do milho aos herbicidas é importante fator que vem sendo estudado por diversos autores (Damião Filho et al., 1996; Green \& Ulrich, 1994; Green, 1998). A inativação metabólica é a base da seletividade de muitos herbicidas comerciais, mas a modificação do sítio-alvo em laboratório tem se tornado prática importante e crescente (Newhouse et al., 1991).

Há consideráveis evidências da tolerância diferencial de cultivares de milho aos herbicidas sulfoniluréias, em especial ao nicosulfuron (Damião Filho et al., 1996; Green \& Ulrich, 1994).

Recebido para publicação em 18/11/1999 e na forma revisada em 30/3/2000.

2 Eng.-Agro., M.S. Pesquisador da Embrapa Milho e Sorgo, Rod. MG 424, km 65, Cx. Postal 151, 35701-970 Sete Lagoas/MG; ${ }^{3}$ Eng.-Agr ${ }^{\circ}$., Bolsista Recém-Doutor, Pesquisador do CNPq/Embrapa Milho e Sorgo; ${ }^{4}$ Eng.-Agr ${ }^{\circ}$., Bolsista Recém-Doutora, Pesquisadora da FAPEMIG/Embrapa Milho e Sorgo. 
O nicosulfuron 2 - [[[][4,6 - dimetoxi - 2 pirimidinil) amino] carbonil] amino] sulfonil] $\mathrm{N}, \mathrm{N}$ - dimetil - 3 - piridinacarboxamida, do grupo químico das sulfoniluréias, é um herbicida de ação em pós-emergência, recomendado para o controle de plantas daninhas na cultura do milho. Ele atua inibindo a síntese de aminoácidos, por meio do bloqueio da enzima acetolactato sintase (ALS), indispensável para a síntese dos aminoácidos essenciais valina, leucina e isoleucina (Hess, 1994). A seletividade da cultura ao nicosulfuron deve-se à capacidade do milho de metabolizar o produto em compostos não-ativos. Cultivares tolerantes parecem metabolizar herbicidas sulfoniluréias mais rapidamente (Green \& Ulrich, 1994).

Em estudos realizados por Monks et al. (1992) com nicosulfuron, aplicado na dose de 35 g i.a. ha ${ }^{-1}$, em oito cultivares de milho doce, verificou-se a morte de uma das cultivares avaliadas, quatro semanas após aplicação. Damião Filho et al. (1996), comparando aspectos biológicos e produtivos de nove diferentes híbridos de milho (BR 106, 205, 201, 206, 92HDIQPM, HT 2X, CMS 473, AG 106 e XL 604), após aplicação da dose de $80 \mathrm{~g}$ i.a. ha ${ }^{-1}$ de nicosulfuron, verificaram que a produtividade estimada dos híbridos não foi afetada pela aplicação do produto.

Devido à tolerância diferencial de híbridos de milho ao nicosulfuron, o potencial de uso e registro deste herbicida deve ser restrito a determinadas cultivares que tolerem o produto (Monks et al., 1992).

O objetivo deste trabalho foi avaliar a tolerância dos híbridos de milho BRS 3060, 3101, 2114 e 2110 a doses crescentes de nicosulfuron.

\section{MATERIAL E MÉTODOS}

O ensaio foi conduzido em campo na área experimental da Embrapa Milho e Sorgo, Sete Lagoas-MG, no ano agrícola 1998/99, em Latossolo Vermelho-Escuro, fase cerrado, com constituição fisica de $73 \%$ de argila, $18 \%$ de silte, $9 \%$ de areia e 2,3\% de carbono orgânico. A temperatura e a precipitação média anual foram de $22,1^{\circ} \mathrm{C}$ e $1.340 \mathrm{~mm}$, respectivamente. Utilizaram-se as cultivares de milho híbrido BRS 3060, 3101, 2114 e 2110, na densidade de 50.000 plantas ha-1 . A adubação utilizada foi de $300 \mathrm{~kg} \mathrm{ha}^{-1}$ da fórmula 4-30-16 + Zn, mais $80 \mathrm{~kg} \mathrm{ha}^{-1}$ de nitrogênio em cobertura, quando as plantas se encontravam no estádio de seis folhas. As doses de nicosulfuron usadas foram de 50, 60 e 70 g i.a. ha ${ }^{-1}(1,25,1,50$ e 1,75 L de Sanson 40 SC, produto comercial, respectivamente), mais um tratamento testemunha que não recebeu aplicação do produto, mas que permaneceu limpo durante todo o ciclo da cultura.

O delineamento experimental foi de blocos ao acaso, em esquema fatorial $4 \times 4$, com três repetições. Cada parcela experimental foi constituída por quatro linhas de $8 \mathrm{~m}$ de comprimento, sendo usadas como área útil as duas linhas centrais, desprezando-se 1 metro de cada extremidade, perfazendo uma área de $10,8 \mathrm{~m}^{2}$.

O nicosulfuron foi aplicado em toda a parcela, utilizando para isso um pulverizador costal pressurizado com $\mathrm{CO}_{2}$ a $30 \mathrm{lb} \mathrm{pol}^{2}$, provido de barra com seis bicos tipo leque 110.02, espaçados de $0,50 \mathrm{~m}$, regulada para vazão de $200 \mathrm{~L} \mathrm{ha}^{-1}$. A aplicação do nicosulfuron foi feita quando as plantas de milho se encontravam no estádio de quatro a seis folhas, ou 20 dias após a emergência das plantas (DAE). As avaliações de fitotoxicidade foram realizadas aos 7, 14 e 21 dias após aplicação (DAP), utilizando como base a escala EWRC (Frans, 1972), modificada (Tabela 1).

Na colheita, foram avaliados os parâmetros altura de planta e de espigas, índice de espigas e produção de grãos corrigida para a umidade de $15,5 \%$.

\section{RESULTADOS E DISCUSSÃO}

Os índices de fitotoxicidade, em diferentes épocas de avaliação para as diferentes cultivares de milho estudadas, estão apresentados na Tabela 2. Observa-se que nenhum dos híbridos apresentou sintomas de fitotoxicidade nas três épocas de avaliação, na dose de $50 \mathrm{~g}$ i.a. ha-1 (1,25 L p.c. ha ${ }^{-1}$ de Sanson), que normalmente é recomendada no estádio inicial das plantas daninhas. Em relação à dose de 60 g i.a. ha-1 (1,50 L p.c. ha ${ }^{-1}$ de Sanson), verificou-se que apenas na primeira avaliação, ou seja, 7 DAP, os híbridos BRS 3060 e 2114 apresentaram sintomas de toxicidade muito leves, de acordo 
com a escala EWRC (Frans, 1972), modificada (Tabela 1). Nas épocas seguintes, de 14 e 21 DAP, ainda na dosagem de 60 g i.a. ha ${ }^{-1}$, não foi verificado efeito fitotóxico para nenhum dos híbridos estudados. Esses resultados estão de acordo com os obtidos por Damião Filho et al. (1996) e Hoogerheide et al. (1997). Os híbridos BRS 3060, 3101 e 2114 apresentaram efeito fitotóxico muito leve na dose de $70 \mathrm{~g}$ i.a. ha ${ }^{-1}$ (1,75 L p.c. ha- ${ }^{-1}$ de Sanson) na primeira avaliação (7 DAP). Nas avaliações feitas aos $14 \mathrm{e}$ 21 DAP, somente o BRS 3060 permaneceu com sintomas de toxicidade muito leves (Tabela 2), concordando com Vicente e Sawada (1997), que também verificaram leve efeito fitotóxico do nicosulfuron, sem comprometer o rendimento de grãos do milho.

Tabela 1 - Índice de avaliação e sua descrição de fitotoxicidade, segundo escala EWRC (Frans, 1972), modificada

\begin{tabular}{|c|c|}
\hline Índice de Avaliação & Descrição da fitotoxicidade \\
\hline 1 & Nula \\
2 & Muito leve \\
3 & Leve \\
4 & Média \\
5 & Forte \\
6 & Muito forte \\
7 & Severa \\
\hline
\end{tabular}

De modo geral, observou-se que, na dose de 50 g i.a. ha-1 (1,25 L p.c. ha-1 de Sanson), nenhum dos híbridos BRS mostrou sintomas de fitotoxicidade devido ao uso do nicosulfuron e que apenas os híbridos BRS 3060 e 2114 apresentaram sintomas muito leves de fitotoxicidade na dose de $60 \mathrm{~g}$ i.a. ha $\mathrm{h}^{-1}$, indicada para situações em que se têm gramíneas e algumas folhas largas de difícil controle. Os resultados indicam que os híbridos BRS 3060, 3101, 2114 e 2110 não são sensíveis ao nicosulfuron, podendo este ser usado com segurança, nas doses recomendadas, para o controle das plantas daninhas.

Embora as avaliações de fitotoxicidade realizadas até 21 DAP não tenham restringido o uso do nicosulfuron nos híbridos estudados, o ensaio foi conduzido até a colheita, em que se avaliaram a altura de planta e espigas, o índice de espigas e a produção de grãos. A análise de variância não revelou efeito significativo para nenhum dos parâmetros estudados. Na Tabela 3, verifica-se que as produtividade médias das cultivares não diferiram entre si, nas diferentes doses de nicosulfuron aplicadas. Esses resultados são concordantes com os de Bastiani et al. (1997), Constantin et al. (1997) e Ferreira et al. (1996), evidenciando que o nicosulfuron não afetou o desenvolvimento e a produção do milho.

Tabela 2 - Índices de fitotoxicidade, em diferentes épocas de avaliação, para as diferentes cultivares de milho BRS submetidas a doses crescentes de nicosulfuron. Embrapa Milho e Sorgo, Sete Lagoas-MG. 1999

\begin{tabular}{|c|c|c|c|c|c|}
\hline \multirow{2}{*}{$\begin{array}{c}\text { Épocas } \\
\text { (DAP) }\end{array}$} & \multirow{2}{*}{ Cultivares } & \multicolumn{4}{|c|}{ Doses de nicosulfuron $\left(\mathrm{g} \mathrm{ha}^{-1}\right)$} \\
\cline { 3 - 6 } 7 & Testemunha & 50 & 60 & 70 \\
\hline \multirow{6}{*}{7} & 3060 & $1 *$ & 1 & 2 & 2 \\
& 2110 & 1 & 1 & 1 & 1 \\
& 3101 & 1 & 1 & 1 & 2 \\
& 2114 & 1 & 1 & 2 & 2 \\
\hline \multirow{6}{*}{14} & 3060 & 1 & 1 & 1 & 2 \\
& 2110 & 1 & 1 & 1 & 1 \\
& 3101 & 1 & 1 & 1 & 1 \\
& 2114 & 1 & 1 & 1 & 1 \\
\hline \multirow{6}{*}{21} & 3060 & 1 & 1 & 1 & 2 \\
& 2110 & 1 & 1 & 1 & 1 \\
& 3101 & 1 & 1 & 1 & 1 \\
& 2114 & 1 & 1 & 1 & 1 \\
\hline
\end{tabular}

* Segundo os índices de fitotoxicidade expressos na Tabela 1.

Tabela 3 - Rendimento médio de grãos de diferentes cultivares de milho submetidas a doses crescentes de nicosulfuron. Embrapa Milho e Sorgo, Sete Lagoas-MG. 1999

\begin{tabular}{|c|c|c|c|c|c|}
\hline \multirow{2}{*}{ Cultivares } & \multicolumn{4}{|c|}{ Rendimento médio de grãos $\left(\mathrm{kg} \mathrm{ha}^{-1}\right)$} & \multirow{2}{*}{ Média } \\
\hline & Testemunha & $* 50 \mathrm{~g}$ & $60 \mathrm{~g}$ & $70 \mathrm{~g}$ & \\
\hline BRS 3060 & 7497 & 8000 & 7312 & 7451 & 7565 \\
\hline BRS 2110 & 6821 & 6123 & 6651 & 6883 & 6620 \\
\hline BRS 2114 & 6960 & 7642 & 6904 & 7741 & 7312 \\
\hline BRS 3101 & 7200 & 7685 & 7549 & 6907 & 7336 \\
\hline Média & 7120 & 7363 & 7104 & 7245 & 7208 \\
\hline $\mathrm{CV}(\%)$ & 8,73 & & & & \\
\hline
\end{tabular}

Planta Daninha, Viçosa-MG, v.18, n.3, p.479-482, 2000 
Com base nos resultados observados, conclui-se que os híbridos de milho BRS 3060, 3101,2114 e 2110 são tolerantes às doses de 50,60 e 70 g i.a. ha ${ }^{-1}$ de nicosulfuron, e apenas o BRS 3060 apresentou sintoma leve de fitotoxicidade até 21 dias após a aplicação, sem comprometer o seu rendimento de grãos.

\section{LITERATURA CITADA}

BASTIANI, M.L.R., SILVA, A.A., FERREIRA, F.A., CARDOSO, A.A. Eficiência do nicosulfuron e sua mistura com atrazine, sobre o controle de plantas daninhas na cultura do milho (Zea mays L.). In: CONGRESSO BRASILEIRO DA CIÊNCIA DAS PLANTAS DANINHAS, 21, 1997, Caxambu. Resumos... Caxambu: SBPCD, 1997. p.199.

CONSTANTIN, J., CONTEIRO, R.L., DEMEIS, M., ITA, A.G. Eficiência e fitotoxicidade do herbicida isoxaflutole + atrazina no controle de plantas daninhas na cultura do milho (Zea mays). In: CONGRESSO BRASILEIRO DA CIÊNCIA DAS PLANTAS DANINHAS, 21, 1997, Caxambu. Resumos....Caxambu: SBPCD, 1997. p. 208.

DAMIÃO FILHO, C.F., MÔRO, F.V., TAVEIRA, L.R. Respostas de híbridos de milho ao nicosulfuron. I - Aspectos biológicos e da produção. Planta Daninha, v.14, n.1, p.3-13, 1996.

FERREIRA, F.A., SILVA, A.A., FERREIRA, L.R. Efeitos do nicosulfuron, em duas formulações, sobre o controle de plantas daninhas na cultura do milho. Ci. Agrotecnol., v. 20, n. 1, p. 19-24, 1996.

FRANS, R.W. Measuring plant response. In: WILKINSON, R.E. Research methods in weed science. Australian: Southern Weed Science Society, 1972. p.28-41.
GREEN, J.M. Differential tolerance of corn (Zea mays) inbreds to four sulfonylurea herbicides and bentazon. Weed Technol., v. 12, p.474-477, 1998.

GREEN, J.M., ULRICH, J.F. Response of maize (Zea mays) inbreds and hybrids to nicosulfuron. Pestic. Sci., v.40, p.187-191, 1994.

HESS, F.D. Mechanism of action of inhibitors of amino acid biosynthesis. In: HERBICIDE action: an intensive course on the activity, selectivity, behavior, and fate of herbicides in plants and soils. West Lafayette: Purdue University, 1994. p.464-507.

HOOGERHEIDE, H.C., VALENTE, T.O., FONTES, A.R. Efeito da mistura pronta isoxaflutole + atrazine no controle de Brachiaria plantaginea, na cultura do milho (Zea mays L.). In: CONGRESSO BRASILEIRO DA CIÊNCIA DAS PLANTAS DANINHAS, 21, 1997, Caxambu. Resumos... Caxambu: SBPCD, 1997. p.214.

MONKS, D.W., MULlinS, C.A., JOHSON, K.E. Response of sweet corn (Zea mays) to nicosulfuron and primsulfuron. Weed Technol., v.6, p.280-283, 1992.

NEWHOUSE, K.E., WANG, T., ANDERSON, P.C. Imidazolinone-resistant crops. In: SHANER, D.L., O'CONNOR, S.L. (Eds.) The imidazolinone herbicides. Boca Raton: CRC Press, 1991. p.139-150.

VICENTE, D., SAWADA, E.M. Efeitos de herbicidas aplicados em pós-emergência no controle de plantas daninhas e seletividade no milho (Zea mays L.) híbrido Ocepar 720. In: CONGRESSO BRASILEIRO DA CIENNCIA DAS PLANTAS DANINHAS, 21, 1997, Caxambu. Resumos... Caxambu: SBPCD, 1997. p.229. 